\title{
Zur Kenntniss der Nitrosoproducte des Phloroglueindiäthyläthers
}

von

\author{
H. Weidel und J. Pollak.
}

Aus dem I. chemischen Laboratorium der k. k. Universität in Wien.

(Vorgelegt in der Sitzung am 18. Juni 1897.)

Vor einiger Zeit hat Moldauer ${ }^{1}$ zwei isomere Mononitrosoverbindungen des Phloroglucin-Diäthyläthers beschrieben, welche er im hiesigen Laboratorium durch Einwirkung von Kaliumnitrit und Essigsäure auf den genannten Äther erhalten hat. Auf Grund der in seiner Arbeit angeführten Versuche konnte er die Behauptung aufstellen, dass die beiden Nitrosoproducte stellungsisomer sind. Es gelang ihm aber weder eine Ortsbestimmung der Nitrosoreste vorzunehmen, noch vermochte er: $z u$ entscheiden, ob die beiden Substanzen als Nitroso- oder Isonitrosoverbindungen zu betrachten sind. Wir haben uns nun die Aufgabe gestellt, diese Fragen einer Erledigung zuzuführen und auch gesucht, die Constitution des in derselben Arbeit beschriebenen, durch die Einwirkung von Kali und Jodäthyl auf das eine der beiden Nitrosoproducte entstehenden Äthyl-Pyriphlorondiäthyläthers aufzuklären und wollen im Folgenden über die Ergebnisse unserer Untersuchung berichten.

Behufs Ermittlung der Stellung des Nitrosorestes haben wir die beiden von Moldauer als $\alpha$ - und $\beta$-Diäthoxychinonoxim bezeichneten Verbindungen der Reduction unterworfen. Beide Producte lassen sich sowohl mit Zinn und Salzsäure, als auch mit Zinnchlorür reduciren. Das Reductionsproduct des

1 Monatshefte für Chemie, 17, 462 . 
a-Diäthoxychinonoxims wurde in Form der Salzsäureverbindung isolirt und unterscheidet sich durch den Gehalt eines Moleküls Krystallwasser und durch die rothe Eisenreaction vom Chlorhydrat des Reductionsproductes des $\beta$-Diäthoxychinonoxims. Beide Aminoverbindungen liefern bei Behandlung mit Essigsäureanhydrid Triacetylderivate, welche sich sowohl durch ihren Habitus, als auch durch ihren Schmelzpunkt scharf von einander unterscheiden.

Der Umstand, dass die beiden Nitrosoverbindungen des Phloroglucindiäthyläthers verschiedene Reductionsproducte und diese wieder differente Acetylderivate liefern, ist beweisend für Mold a u er's Ansicht, dass die Nitrosokörper nicht stereoisomer sein können. Henrich erhielt aus den zwei verschiedenen, aber stellungsidentischen Mononitroso-Orcinen, welche bei Einwirkung von salpetriger Säure auf Orcin gebildet werden, bei der Reduction gleiche Producte.

Was nun zunächst die Stellung der Amidogruppen in den beiden Reductionsproducten angeht, so sind nur zwei Möglichkeiten vorhanden: es kann sich dieselbe zwischen einer Äthoxylgruppe und der Hydroxylgruppe oder aber zwischen den beiden Äthoxylgruppen befinden. Die Chlorhydrate müssten demzufolge nach den folgenden Formeln
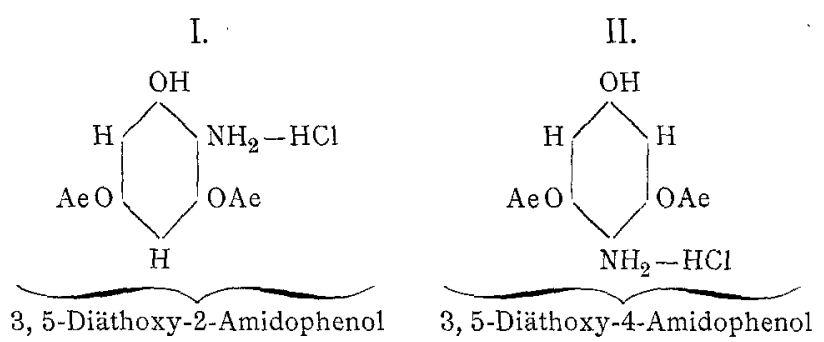

constituirt sein.

Ein nach der Formel I zusammengesetzter Körper sollte bei der Acetylirung eine Äthenylverbindung liefern. Bei den diesbezüglichen Versuchen wurde aber aus keinem der beiden Chlorhydrate ein Äthenylderivat erhalten, trotz der mannigfaltigsten Variationen der Reactionsbedingungen; unter allen

1. Monatshefte für Chemie, $18,142$. 
Umständen wurden aus beiden Verbindungen Triacetylproducte gewonnen und darum liess sich auf diesem Wege eine Entscheidung der Stellungsfrage nicht herbeiführen. Mit positivem Erfolge haben wir aber die Einwirkung von Harnstoff auf die Chlorhydrate der beiden Reductionsproducte vorgenommen. Dabei war zu erwarten, dass das nach Formel I constituirte Amidophenol analog wie das o-Amidophenol ${ }^{1}$ das folgende Carbonylderivat liefert:

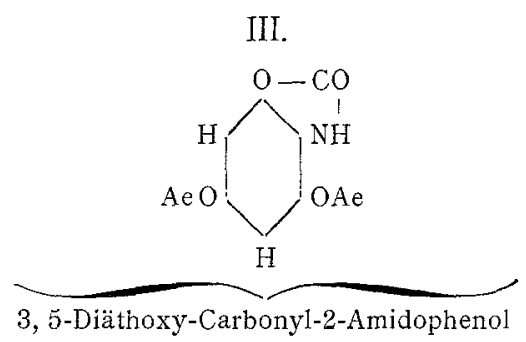

während die Verbindung II durch Behandlung die Entstehung eines nach der Formel

IV.<smiles>CC(=O)OC1CCCC1NC(N)=O</smiles>

zusammengesetzten substituirten Harnstoffes erwarten liess. Thatsächlich gab das Chlorhydrat des Reductionsproductes des a-Diäthoxychinonoxims beim Zusammenschmelzen mit Harnstoff das nach Schema III constituirte Carbonylderivat, während das aus dem $\beta$-Diäthoxychinonoxim dargestellte Reductionsproduct einen substituirten Harnstoff lieferte. Mit Rücksicht auf diese Ergebnisse erscheint die Verschiedenheit der Stellung der $\mathrm{NH}_{2}$-Gruppe in den beiden Reductionsproducten festgestellt zu sein. Der Umstand, dass bei der Einwirkung von Essigsäure auf das 3,5-Diäthoxy-o-Amidophenol die zu erwartende Äthenylverbindung nicht gebildet wurde, spricht nicht gegen die entwickelte Auffassung, zumal in der Literatur eine Reihe von

1 Sandmeyer, B. B: 19, 2656. 
Beobachtungen verzeichnet sind, ${ }^{1}$ bei welchen durch die Einwirkung von Essigsäure oder Essigsäureanhydrid auf Amidophenole die Bildung von Äthenylverbindungen nicht erfolgte, obwohl die $\mathrm{NH}_{2}$-Gruppe zum $\mathrm{OH}$ zweifellos in der Orthostellung sich befunden hat.

Durch die Klarlegung der Constitution der beiden Amidoverbindungen sind auch die Producte der Einwirkung von salpetriger Säure auf den Phloroglucindiäthyläther hinsichtlich ihrer Stellung bestimmt, und es erübrigt nur noch den Nachweis $\mathrm{zu}$ führen, ob dieselben als Nitroso- oder Isonitrosoverbindungen (Oxime) zu betrachten sind. Die Entscheidung hierüber konnte in folgender Weise getroffen werden. Die beiden Nitrosoproducte lassen sich, wie Moldauer tereits gefunden hat, durch Kali und Jodäthyl weiter äthyliren, und zwar bildet sein $\alpha$-Diäthoxychinonoxim neben Äthyl-PyriphloronDiäthyläther einen roth gefärbten Triäthyläther, während das $\beta$-Diäthoxychinonoxim ausschliesslich eine gelbe Triäthylverbindung liefert. Diese beiden Triäthyläther können mit Rücksicht auf die Constitution der Amidoproducte nur nach den folgenden Formeln<smiles>CCO[W]1C=CC(=O)OC1=O</smiles>

VII.

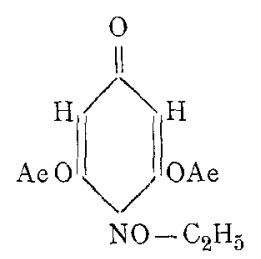

VI.<smiles></smiles>

VIII.<smiles></smiles>

zusammengesetzt sein.

1 Bamberger, B. 16, 2401; Liebermann und Kostanecky, B. 17, 886; Nietzki und Benckiser, B. 18, 503; Nietzki und Preussen, B. 19, 2248; Nietzki und Schmidt, B. 21, 1852; Friedländer und Zeitlin, 
Durch Reduction müssten aus diesen Triäthoxyverbindungen, falls sie nach den Formeln VI und VIII gebaut sind, Amidoproducte entstehen, in welchen drei C-Atome mit drei $\mathrm{OC}_{2} \mathrm{H}_{5}$-Resten in Verbindung sind, im anderen Falle ( $\mathrm{V}$ und VII) müsste unter Alkoholabspaltung die Bildung von Reductionsproducten eintreten, welche identisch sind mit jenen, die wir aus den Nitrosoderivaten direct erhalten haben. Die Versuche, bei welchen wir Zinnchlorür als Reductionsmittel in Anwendung brachten, zeigten, dass die beiden Triäthoxyderivate unter Austritt von Alkohol die früher erwähnten Amidoproducte bilden, welche nur zwei $\mathrm{OC}_{2} \mathrm{H}_{5}$-Reste enthalten. ${ }^{1}$ Dadurch ist es erwiesen, dass die Triäther nicht nach den Formeln VI und VIII constituirt sein können, dass sie eine abspaltbare, mit dem $\mathrm{N}$ in directer Bindung stehende $\mathrm{OC}_{2} \mathrm{H}_{5}$-Gruppe enthalten und somit als Oximäther, beziehungsweise als Isonitrosoderivate $z u$ betrachten sind, welchen die Formeln V und VII zugesprochen werden müssen, und daraus ergibt sich endlich, dass die Producte der Einwirkung von salpetriger Säure auf den Phloroglucindiäthyläther ebenfalls als Isonitrosoverbindungen, beziehungsweise Oxime anzusprechen sind. Moldauer's $\alpha$-Diäthoxychinonoxim ist mit Rücksicht auf die Constitution des Reductionsproductes als

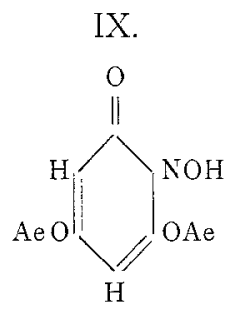

3,5-Diäthoxy-Ortho-Chinon-2-Monoxim zu bezeichnen, während das $\beta$-Diäthoxychinonoxim als

B. 27, 195; Kehrmann und Tiesler, J. pr. Chem. (2), 40, 489; Cazeneuve, B1. (3), 9, 34; Hodgkinson und Limpach, Soc. 63, 106; Mazzara, G. Chim. 19,66; Oettinger, M. f. Chem. 16, 262.

I In beiden Fällen wurde die Identität der Reductionsproducte der Triäthoxyverbindungen mit denjenigen der Oxime durch Darstellung der Triacetylderivate aus beiden Körperpaaren sicher festgestellt. 


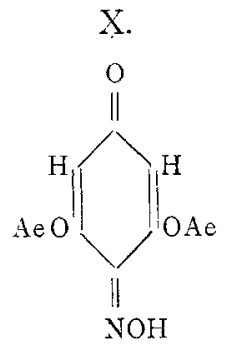

3, 5-Diäthoxy-Para-Chinon-4-Monoxim aufzufassen ist.

Mit der Feststellung der Constitution des Diäthoxy-o-Chinon-2-Monoxims ist auch die des Äthyl-Pyriphlorondiäthyläthers $\left(\mathrm{C}_{6}\left(\mathrm{C}_{2} \mathrm{H}_{5}\right) \mathrm{NO}\left\{\begin{array}{l}\mathrm{OC}_{2} \mathrm{H}_{5} \\ \mathrm{OC}_{2} \mathrm{H}_{5}\end{array}\right)\right.$, welcher bei der Einwirkung von Kali und Jodäthyl auf das Oxim neben dem Oximester gebildet wird, bis zu einem gewissen Grade gegeben, insofern, als die Stellung des Stickstoffes bestimmt erscheint. Zur weiteren Aufklärung wurde die Verbindung der Einwirkung reducirender Agentien unterworfen. Dabei erhielten wir jedoch keine wasserstoffreicheren Producte, sondern es vollzog sich eine Wasseranlagerung oder eine Spaltung. Bei Behandlung mit Natriumamalgam erhielten wir im Sinne der Gleichung

$$
\underbrace{\mathrm{C}_{12} \mathrm{H}_{15} \mathrm{NO}_{3}}_{\begin{array}{c}
\text { Athyl-Pyri- } \\
\text { phloron- } \\
\text { diäthyläther }
\end{array}}+\mathrm{H}_{2} \mathrm{O}=\mathrm{C}_{6} \mathrm{H}_{2}\left(\mathrm{OC}_{2} \mathrm{H}_{5}\right)_{2}\left\{\begin{array}{l}
\mathrm{NH}-\mathrm{CO}-\mathrm{CH}_{3} \\
\mathrm{OH}
\end{array}\right.
$$

eine um den Mehrgehalt von $\mathrm{H}_{2} \mathrm{O}$ vom Ausgangsmaterial unterschiedene Verbindung, welche beim Erhitzen mit Schwefelsäure Essigsäure abspaltet und die der Einwirkung von Essigsäureanhydrid unterworfen ein Acetylproduct lieferte, das mit dem Triacetylproducte des 3, 5-Diäthoxy-o-Amidophenol identificirt werden konnte. Das Wasseranlagerungsproduct des Äthylpyriphlorondiäthyläthers ist somit als das Monoacetylderivat des 3,5-Diäthoxy-2-Amidophenol zu betrachten. Schon diese Beobachtungen zeigen, dass das Pyriphloron den von Mold a u er angenommenẹ Doppelring nicht enthalten kann, sondern völlig anders constituirt sein muss. Durch Erhitzen des Pyriphlorons mit Zinn und Salzsäure erhielten wir das Chlorhydrat des 
3,5-Diäthoxy-2-Amidophenols, welche Verbindung indess auch bei anhaltender Einwirkung von mässig concentrirter Salzsäure entsteht. Offenbar findet auch bei diesen Reactionen erstlich die Anlagerung von Wasser statt und wird das Monoacetylderivat dann durch weitere Hydrolyse entsprechend der Gleichung

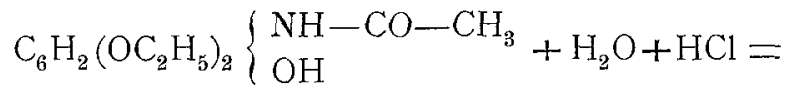

$$
\begin{aligned}
& =\mathrm{C}_{2} \mathrm{H}_{4} \mathrm{O}_{2}+\underbrace{\mathrm{C}_{6} \mathrm{H}_{2}\left(\mathrm{OC}_{2} \mathrm{H}_{5}\right)_{2}}_{\text {3, 5-Diäthoxy-2-Amidophenol }}\left\{\begin{array}{l}
\mathrm{NH}_{2}-\mathrm{HCl} \\
\mathrm{OH}
\end{array}\right.
\end{aligned}
$$

gespalten. Thatsächlich konnten wir die reichlich entstandene Essigsäure im Destillate mit Hilfe des Silbersalzes nachweisen.

Die mitgetheilten Ergebnisse klären die Constitution des Äthylpyriphloron-Diäthyläther völlig auf, umsomehr, als das Monoacetylderivat des 3,5-Diäthoxy-2-Amidophenol beim Destilliren unter Wasserabspaltung das Pyriphloron regenerirt; es muss ihm die Formel<smiles>CC1ON2C(=O)OCC12</smiles>

zugesprochen werden und ist dasselbe als 3, 5-DiäthoxyÄthenyl-2-Amidophenol zu betrachten. Das angegebene Schema lässt alle Reactionen leicht erklären. Durch Einwirkung von Natriumamalgam, wohl auch von Natronhydroxyd, wird zunächst das vorerwähnte Monoacetylproduct erzeugt, ein Verhalten, welches die meisten Äthenylverbindungen von o-Amidophenolderivaten zeigen. Auch die von Moldauer beobachtete Bildung eines Chlorhydrates und eines Platindoppelsalzes ist verständlich, da bekanntlich derartige Anhydrokörper zur Salzbildung befähigt sind.

Die ungewöhnliche Bildungsweise eines Äthenylderivates durch die Einwirkung von alkoholischem Kali und Jodäthyl 
auf ein Oxim lässt sich in folgender Weise interpretiren. Es kann durch den Einfluss des alkoholischen Kalis, beziehungsweise des Kaliumäthylats in der Art, wie dies bei der Bildung der Azoverbindungen aus den Nitrokörpern geschieht, eine Reduction eintreten, bei welcher ein Theil des Alkohols zu Essigsäure oxydirt wird, welche mit dem intermediär auftretenden Reductionsproducte unter den später anzugebenden Versuchsbedingungen das 3,5-Diäthoxy-Äthenyl-2-Amidophenol bildet. Anderseits ist aber die Möglichkeit nicht ausgeschlossen, dass das 3,5-Diäthoxy-o-Chinonoxim bei der Esterification zum Theil in der tautomeren Form als wahres Nitrosoproduct reagirt und einen wahren Triäthyläther liefert, in welchen das dritte Äthoxyl am Kohlenstoff gebunden ist; dieser Äther könnte nun im Sinne des folgenden Schemas

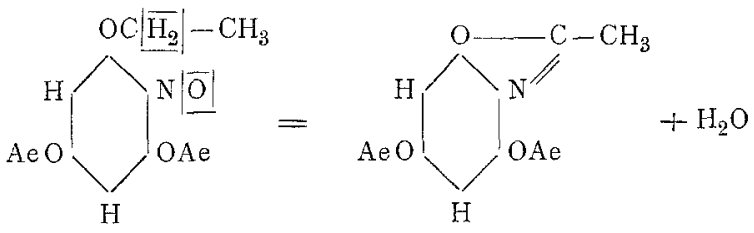

unter Wasserabspaltung die Äthenylverbindung bilden. Für letztere Entstehungsweise scheint die Thatsache zu sprechen, dass es in keiner Weise gelingt, den 3,5-Diäthoxy-o-Chinonmonoximester in die Äthenylverbindung überzuführen.

Wir wollen nun mit der Beschreibung unserer Versuchsergebnisse beginnen, vorerst aber die Darstellung des Phloroglucindiäthyläthers genau beschreiben, da durch die Verbesserung des von Moldauer angegebenen Verfahrens nicht nur der Äther fast quantitativ gewonnen werden kann, sondern es auch möglich wird, die dabei entstehenden Nebenproducte $\mathrm{zu}$ isoliren.

\section{Darstellung des Phloroglucindiäthyläthers.}

Die Darstellung des Diäthyläthers des Phloroglucins erfolgte nach dem Verfahren von Will und Albrecht ${ }^{1}$ aus 
käuflichem diresorcinhältigen Phloroglucin, wobei nachfolgende Abänderung, die sich als besonders vortheilhaft erwies, in Anwendung kam. Das Phloroglucin wurde in der zehnfachen Menge absoluten Alkohols gelöst, die Lösung zunächst bei gewöhnlicher Temperatur mit Salzsäure gesättigt, hierauf am Rückflusskühler gekocht, bis nahezu keine Salzsäure entweicht, endlich blieb die neuerlich bei Zimmertemperatur gesättigte Lösung noch etwa 12 Stunden stehen. Um die Destillation mit Wasserdampf, welche Moldauer zur Darstellung des Äthers in Anwendung brachte, bei welcher die Nebenproducte grösstentheils zersetzt werden, zu umgehen, wurde die alkoholische Lösung im Vacuum vollkommen abdestillirt und der Rückstand hierauf in Äther aufgenommen. Diese Lösung schüttelt man mit Wasser, um die letzten Reste der Salzsäure und eine nicht näher, untersuchte, in sehr kleinen Mengen vorhandene Substanz zu entfernen. Nach vollständiger Vertreibung des Äthers wurde die dunkelbraungelb gefärbte zähe Masse in Wasser vertheilt und mit Benzol zwei- bis dreimal ausgeschüttelt. ${ }^{1}$ Der wässerige Theil $(A)$, in welchem eine grössere Quantität einer ungelösten, krystallinischen Substanz suspendirt war, wurde von der Benzollösung getrennt. Diese gibt nach dem Abdestilliren einen bald krystallisirenden Rückstand $(B) . B$ ist fast reiner Diäthyläther des Phloroglucins, welcher zur vollständigen Reinigung der Destillation im Vacuum unterworfen wurde, wobei er den constanten Siedepunkt von $188-190^{\circ}$ C. bei $20 \mathrm{~mm}$ Druck zeigte. Das Destillat erstarrt zu einer strahligkrystallisirten, gelblichweissen Masse, die, in Äther gelöst, beim langsamen Abdunsten grosse, stark glasglänzende Krystalle liefert, die von Herrn Hofrath v. Lang einer krystallographischen Untersuchung unterworfen wurden.

»Die Krystalle gehören in das tetragonale System. Beobachtet wurden die Formen 100,110, 111, 311. Durch die gleich starke Entwicklung der Formen 100 und 111 bekommen die Krystalle einen dodekaëderähnlichen Habitus. Die Form 311 tritt in genau symmetrischer Entwicklung auf.

$1 \mathrm{Da}$ das dritte Benzolextract in der Regel nur ganz geringe Mengen an Diäthyläther enthielt, so erwies sich ein weiteres Extrahiren überflüssig. 
Gemessen wurden die Winkel:

$$
\begin{aligned}
& 111 . \overline{1} 11=30^{\circ} 20^{\prime} \\
& 111.110=68^{\circ} 21^{\prime}\left(68^{\circ} 17^{\prime} \text { gerechnet }\right) .
\end{aligned}
$$

Dem ersten Winkel entspricht das Axenverhältniss:

$$
a: c=1: 0 \cdot 2817 .
$$

Der Schmelzpunkt dieses absolut reinen Productes liegt bei $88-89^{\circ}$ C. (uncorr.). ${ }^{1}$ Die Ausbeute an diesem Präparate war etwa $144-150 \mathrm{~g}$ aus $200 \mathrm{~g}$ krystallwasserhältigem Phloroglucin.

$$
\text { Untersuchung von } A \text {. }
$$

Der mit $(A)$ bezeichnete Theil besteht aus einer Lösung $(a)$, in welcher eine ungelöste Substanz $(b)$ suspendirt ist, die nach dem Abfiltriren durch wiederholtes Umkrystallisiren aus siedendem Wasser in Form weisser Nadeln erhalten wurde, deren Schmelzpunkt über $300^{\circ}$ liegt. Sie zeigen die von Herzig und $Z$ eis $1^{2}$ angegebene Diresorcinreaction und geben bei der Analyse Zahlen, die vollkommen genau auf Diresorcin stimmen.

\begin{tabular}{|c|c|c|}
\hline & Gefunden & $\begin{array}{l}\text { Berechnet } \\
\text { für } \mathrm{C}_{12} \mathrm{H}_{10} \mathrm{O}_{4}\end{array}$ \\
\hline$\ldots \ldots$ & $65 \cdot 75$ & $66 \cdot 05$ \\
\hline$H \ldots \ldots \ldots$ & $4 \cdot 88$ & $4 \cdot 58$ \\
\hline
\end{tabular}
$0.2291 \mathrm{~g}$ bei $100^{\circ}$ getrockneter Substanz gaben $0.5524 \mathrm{~g}$ Kohlensäure und $0.1008 \mathrm{~g}$ Wasser.

In 100 Theilen:

Auch die Krystallwasserbestimmung ergab das richtige Resultat.

$0 \cdot 7990 \mathrm{~g}$ lufttrockener Substanz verloren beim Stehen über Schwefelsäure $0.1117 \mathrm{~g}$ Wasser.

In 100 Theilen:

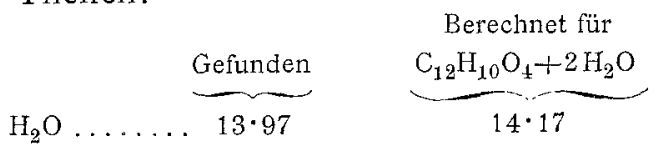

1 Der bisher angegebene Schmelzpunkt von $75^{\circ} \mathrm{C}$. dürfte aller Wahrscheinlichkeit nach auf eine kleine Verunreinigung der Präparate zurückzuführen sein, welche in der durch Destillation gewonnenen Substanz nicht enthalten ist.

2 Monatshefte für Chemie, 11, 421. 
Die vom Diresorcin abgesaugte wässerige Lösung (a) schied beim Einengen lange, derbe, gut ausgebildete, noch schwach gelblich gefärbte Krystallnadeln ab. Trotzdem dieselben in siedendem Benzol schwer löslich sind, haben wir die Substanz im Soxhlet'schen Apparate mit diesem Lösungsmittel anhaltend extrahirt. Nach dem Abdestilliren scheidet sich die Verbindung in Form feiner, ganz farbloser, verfilzter Krystallnadeln ab, die nochmals aus Wasser umkrystallisirt und über Schwefelsäure getrocknet den constanten Schmelzpunkt von $72-73^{\circ} \mathrm{C}$. (uncorr.) zeigten. Die Analysen, die sowohl mit Substanzen, welche aus Benzol, als auch mit solchen, welche zuletzt aus Wasser umkrystallisirt waren, vorgenommen wurden, gaben Zahlen, die auf den bisher unbekannten Monoäthyläther des Phloroglucins $\mathrm{C}_{6} \mathrm{H}_{3}(\mathrm{OH})_{2} \mathrm{OC}_{2} \mathrm{H}_{5}$ stimmten. Für die Analyse wurde die Substanz über Schwefelsäure bis zur Gewichtsconstanz getrocknet.

I. $0 \cdot 1974 \mathrm{~g}$ Substanz gaben $0 \cdot 4474 \mathrm{~g}$ Kohlensäure und $0 \cdot 1131 \mathrm{~g}$ Wasser.

II. $0 \cdot 2314 g$ Substanz gaben $0 \cdot 5248 g$ Kohlensäure.

In 100 Theilen:

\begin{tabular}{|c|c|c|c|}
\hline \multicolumn{4}{|c|}{ Gefunden } \\
\hline & I & II & $\underbrace{\text { Berechnet }}$ \\
\hline C & $61 \cdot 81$ & $61 \cdot 85$ & $62 \cdot 33$ \\
\hline$H \ldots \ldots$ & $6 \cdot 36$ & - & $6 \cdot 49$ \\
\hline
\end{tabular}

Auch die Äthoxylbestimmungen, welche in diesem Falle ausschlaggebend sind, gaben ein mit der Theorie vollkommen übereinstimmendes Resultat.

I. $0 \cdot 2145 \mathrm{~g}$ Substanz gaben $0 \cdot 3283 \mathrm{~g}$ Jodsilber.

II. $0 \cdot 2050 \mathrm{~g}$ Substanz gaben $0 \cdot 3105 \mathrm{~g}$ Jodsilber.

In 100 Theilen:

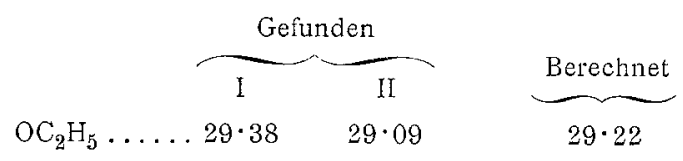

Die Krystallwasserbestimmung der lufttrockenen Substanz zeigte, dass dieselbe 2 Moleküle Krystallwasser enthielt. 
I. $09748 \mathrm{~g}$ Substanz verloren beim Stehen über Schwefelsäufe $0.18+2 \mathrm{~g}$ Wasser.

II. $0.6790 \mathrm{~g}$. Substanz verloren beim Stehen über Schwefelsäure $0.1280 \mathrm{~g}$ Wasser.

In 100 Theilen:

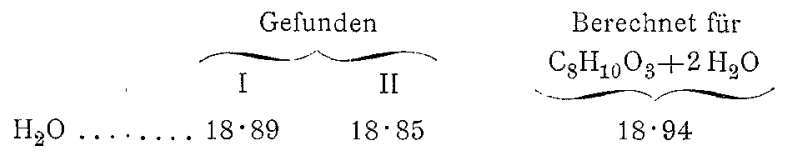

Der Monoäthyläther des Phloroglucins gibt wie das Phloroglucin und wie der Phloroglucindiäthyläther mit Salzsäure vermischt die rothe Fichtenspanreaction.

Der Hauptvortheil unserer Äthylirungsmethode besteht darin; dass dieselbe die Isolirung des Diresorcins und des bisher unbekannt gebliebenen Monoäthyläthers gestattet. Gleichzeitig dürfte dieses Verfahren das einzige sein, bei welchem es möglich ist, eine annähernde Bestimmung des Diresorcingehaltes des käuflichen Phloroglucins vorzunehmen, allerdings ist auch diese nicht ganz genau, da eine geringe Menge des Diresorcins in Wasser gelöst bleibt und von den ersten Partien des Monoäthyläthers, mit denen sie sich beim Einengen gemeinsam ausscheidet, erst durch Umkrystallisiren getrennt werden kann. Bei Vernachlässigung dieser kleinen Menge stellt sich der Diresorcingehalt eines guten käuflichen Phloroglucins auf etwa $12 \%$, wir verarbeiteten aber auch Handelsproducte, die bis zu 30\% Diresorcin enthielten. Von dem nach Abzug des Diresorcins übrigbleibenden Phloroglucin war im Durchschnitt bei unseren Versuchen $78 \%$ in den Diäthyläther und circa $12 \%$ in den Monoäthyläther verwandelt worden, wobei stets die Rohproducte der Berechnung zu Grunde liegen.

\section{Einwirkung von salpetriger Säure auf den Phloroglucin- diäthyläther:}

Durch kleine Abänderungen des von Moldauer beschriebenen Nitrosirungsverfahrens gelingt es, bessere Ausbeuten und reinere Producte zu erhalten. Am zweckmässigsten erwiesen sich die folgenden Verhältnisse: 
Je $25 \mathrm{~g}$ Phloroglucindiäthyläther, die in $160 \mathrm{~cm}^{3}$ absoluten Alkohol gelöst sind, werden mit $26 \mathrm{~cm}^{3}$ Eisessig versetzt. Nachdem diese Lösung durch Einstellen in eine Kältemischung auf $0^{\circ} \mathrm{C}$. abgekühlt ist, trägt man eine Lösung von $26 \mathrm{~g}$ Kaliumnitrit (72 procentig) in $50 \mathrm{~cm}^{3}$ Wasser mit der Vorsicht ein, dass die Temperatur der Masse während des Eintragens nicht über $2^{\circ} \mathrm{C}$. steigt. Dabei färbt sich die Flüssigkeit schwach gelbroth unt nimmt nach einigen Stunden eine dunkelrothe Farbe an; es beginnt die Abscheidung von langen Krystallnadeln, die sich bald so vermehren, dass das Ganze zu einem Brei gesteht. Nach 3-4 Stunden wird der feurigrothe Krystallkuchen mit $200 \mathrm{~cm}^{3}$ Eiswasser angerührt, hierauf abgesaugt und mit Eiswasser völlig ausgewaschen. Durch diese Abänderung erreichten wir, dass der gesammte Diäthyläther nitrosirt wurde, während bei der ursprünglichen Methode stets kleine Mengen desselben unverändert blieben.

Das so erhaltene Gemisch der beiden Oxime wurde noch feucht aus Alkohol umkrystallisirt und betrug die Menge desselben nach dem Trocknen über Schwefelsäure im Vacuum etwa $95 \%$ der theoretischen Ausbeute. Dieses Rohproduct wird genau nach der Vorschrift Moldauer's wiederholt mit absolutem Äther geschüttelt, wobei sich das 3, 5-Diäthoxyortho-Chinon-2-Monoxim löst, das 3,5-Diäthoxy-para-Chinon4-Monoxim hingegen ungelöst bleibt. Die Ausbeute an ersterem beträgt $70-75 \%$ des Rohproductes. Beide Oxime wurden durch wiederholtes Umkrystallisiren aus Alkohol gereinigt und zeigten hierauf die von Moldauer angegebenen Eigenschaften.

Durch Behandlung des 3,5-Diäthoxy-ortho-Chinon-2Monoxims mit reducirenden Agentien erhielten wir das

\section{3, 5-Diäthoxy-2-Amidophenolchlorhydrat.}

Beim Eintröpfeln einer mässig concentrirten, mit etwas Salzsäure versetzten Zinnchlorürlösung in die verdünnt alkoholische Lösung des 3,5-Diäthoxy-ortho-Chinon-2-Monoxims tritt völlige Entfärbung der gelbrothen Flüssigkeit ein, sowie ein kleiner Überschuss des Reduc tionsmittels vorhanden ist. Nach Eintritt dieser leicht zu beobacl tenden Endreaction wurde die überschüssige Salzsäure und ier Alkohol im Vacuum 
abdestillirt. Der krystallinische, in Wasser gelöste Rückstand wird mit Schwefelwasserstoffgas zersetzt. Das Filtrat vom Schwefelzinn ist luftempfindlich und muss daher im Vacuum eingedampft werden. Da das Chlorhydrat des 3, 5-Diäthoxy2-Amidophenols nicht allzu leicht löslich ist, so scheiden sich schon beim Concentriren feine, farblose Krystallnadeln ab. Der Trockenrückstand, welcher nach dem Abdunsten hinterbleibt, wird nochmals aus wenig salzsäurehältigem Wasser umkrystallisirt. Die sich nun abscheidenden feinen, schwach seidenglänzenden, verfilzten Nadeln werden beim Liegen an der Luft bald rosenroth und schliesslich braun. Die wässerige Lösung derselben gibt auf Zusatz von Eisenchlorid eine tief kirschrothe Farbe. Beim Erhitzen zersetzt sich die Substanz oberhalb $130^{\circ}$, ohne zu schmelzen. Sie enthält kein Krystallwasser. Die im Vacuum über Schwefelsäure getrocknete Verbindung gab bei der Analyse und bei der Äthoxylbestimmung Zahlen, die zur Formel $\mathrm{C}_{6} \mathrm{H}_{2}\left(\mathrm{OC}_{2} \mathrm{H}_{5}\right)_{2} \mathrm{OH} \cdot \mathrm{NH}_{2}$. $\mathrm{HCl}$ führten.

I. $0.2326 g$ Substanz gaben $0.4363 g$ Kohlensäure und $0.1458 g$ Wasser.

II. $0 \cdot 3181 \mathrm{~g}$ Substanz gaben $0 \cdot 1956 \mathrm{~g}$ Chlorsilber.

III. $0.2113 \mathrm{~g}$ Substanz gaben $0.4175 \mathrm{~g}$ Jodsilber.

In 100 Theilen:

\begin{tabular}{|c|c|c|c|}
\hline \multicolumn{4}{|c|}{ Gefunden } \\
\hline I & II & III & Berechnet \\
\hline$C \ldots \ldots \ldots 51 \cdot 15$ & - & - & $51 \cdot 39$ \\
\hline $\mathrm{H} \ldots \ldots \ldots 6 \cdot 96$ & - & - & $6 \cdot 85$ \\
\hline $\mathrm{Cl} \ldots \ldots \ldots-$ & $15 \cdot 21$ & 一 & $15 \cdot 20$ \\
\hline $\mathrm{OC}_{2} \mathrm{C}_{5} \ldots \ldots-$ & - & $37 \cdot 95$ & $38 \cdot 54$ \\
\hline
\end{tabular}

Das 3,5-Diäthoxy-2-Amidophenol konnte seiner leichten Zersetzlichkeit und Luftempfindlichkeit halber im freien $\mathrm{Zu}-$ stande nicht isolirt werden. Beim Versetzen einer concentrirten Lösung des Chlorhydrates mit der erforderlichen Menge einer Ätzkali- oder Natriumcarbonatlösung färbt sich die Flüssigkeit gelblichroth, weiterhin dunkelroth, schliesslich braun und scheidet dunkle humöse Flocken ab.

Das Chlorhydrat gab beim Behandeln mit Essigsäureanhydrid ein Triacetylderivat. Nach mehrstündigem Erhitzen des Chlorhydrates mit der 25 fachen Menge Essigsäureanhydrid 
auf den Siedepunkt des letzteren hinterbleibt beim Abdestilliren des Anhydrids im Vacuum ein ziemlich stark gefärbter Rückstand, der nach kurzer Zeit krystallinisch erstarrt. Er wird in Ligroin in der Siedehitze gelöst, wobei die Verunreinigungen zurückblieben. Die sich, beim theilweisen Verdunsten des Lösungsmittels ausscheidenden Krystalle werden wiederholt aus Ligroin umkrystallisirt und bilden endlich $\mathrm{zu}$ kleinen Drusen verwachsene Krystallnadein, die bei $110-112^{\circ} \mathrm{C}$. (uncorr.) schmelzen.

Die mit der über Schwefelsäure im Vacuum getrockneten Substanz vorgenommene Analyse zeigte so wie die Äthoxylund Acetylbestimmung, dass dieselbe ein Triacetylderivat ist, welchem die Formel $\mathrm{C}_{6} \mathrm{H}_{2}\left(\mathrm{OC}_{2} \mathrm{H}_{5}\right)_{2} \mathrm{O} . \mathrm{CO} \cdot \mathrm{CH}_{3} \mathrm{~N}$. $\left(\mathrm{COCH}_{3}\right)_{2}$ zukommt.

I. $0.2554 \mathrm{~g}$ Substanz liefern $0.5568 \mathrm{~g}$ Kohlensäure und $0.1556 \mathrm{~g}$ Wasser.

II. $0 \cdot 2642 g$ Substanz liefern $0.3873 g$ Jodsilber.

III. $0.3007 \mathrm{~g}$ Substanz liefern Essigsäure, welche $68.2 \mathrm{~cm}^{3} 1 / 25$ norm. Kalilauge neutralisirt, entsprechend $0.117304 \mathrm{~g}$ Acetyl.

In 100 Theilen:

\begin{tabular}{|c|c|c|c|c|}
\hline & \multicolumn{3}{|c|}{ Gefunden } & \multirow{2}{*}{ Berechnet } \\
\hline & I & II & III & \\
\hline$C \ldots$. & $.59 \cdot 45$ & - & - & $59 \cdot 44$ \\
\hline $\mathrm{H}, \ldots$. & . $6 \cdot 76$ & - & - & $6 \cdot 50$ \\
\hline $\mathrm{OC}_{2} \mathrm{H}_{5}$. & - & $28 \cdot 22$ & - & $27 \cdot 86$ \\
\hline $\mathrm{CH}_{3} \mathrm{CO}$ & - & - & $39 \cdot 011$ & $39 \cdot 93$ \\
\hline
\end{tabular}

Die Reduction des 3, 5-Diäthoxy-para-Chinon-4-Monoxims lieferte das

\section{3, 5-Diäthoxy-4-Amidophenolchlorhydrat.}

Die Reduction wurde in fast gleicher Wejse, wie früher angegeben, vorgenommen. Die mit Wasser verdünnte, alko-

1 Die Acetylbestimmungen dieser und der folgenden Substanzen konnten nicht nach den gebräuchlichen Methoden (Verseifung mittelst Hydroxyden und Bestimmung der Essigsäure durch Destillation) vorgenommen werden, da in Folge der Zersetzung des Phloroglucinrestes unter Bildung flüchtiger Säuren unbrauchbare Werthe erhalten wurden. Durch Anwendung einer neuen äusserst einfachen Acetylbestimmungsmethode, die demnächst veröffentlicht werden soll, gelang es nicht nur bei unseren Substanzen, sondern auch bei zahlreichen anderen Acetylproducten genau übereinstimmende Werthe zu erzielen. 
holische, lichtgelb gefärbte Lösung wird durch Zinnchlorür, sowie die theoretische Menge eingetragen ist, vollständig entfärbt. Die Endreaction ist wegen der weniger satten Färbung nicht so scharf wie beim 3,5-Diäthoxy-ortho-Chinon-2-Monoxim. Hierauf wird in die Lösung Schwefelwasserstoffgas eingeleitet. Obzwar die Luftempfindlichkeit des 3, 5-Diäthoxy4-Amidophenolchlorhydrats wesentlich geringer ist wie die des vorigen Productes, muss man doch das Abdestilliren der vom Schwefelzinn filtrirten, vollkommen farblosen Flüssigkeit im Vacuum vornehmen. Der krystallinische Rückstand wird in der eben erforderlichen Menge heissen Wassers unter Zusatz von einigen Tropfen Salzsäure gelöst und eventuell vom Schwefel abfiltrirt. Beim Abkühlen scheiden sich lebhaft glänzende, lange, farblose, anscheinend monokline Krystallnadeln $a b$, die in Wasser leicht löslich sind. Die wässerige Lösung gibt mit Eisenchlorid keine Farbenreaction.

Diese vollkommen reine Substanz zersetzt sich beim Erhitzen, ohne zu schmelzen, bei circa $140^{\circ}$. Die Verbindung enthält ein Molekül Krystallwasser, welches sie im Vacuum nicht abgibt, wohl aber bei $100^{\circ}$ sowohl ohne, als auch mit Vacuum, nur entweicht hiebei auch etwas Salzsäure. Aus diesem Grunde mussten die Äthoxylbestimmung und die Analyse mit der krystallwasserhältigen, im Vacuum zur Gewichtsconstanz gebrachten Substanz vorgenommen werden. Die hiebei erhaltenen Zahlen stimmen auf die Formel $\mathrm{C}_{6} \mathrm{H}_{2}\left(\mathrm{OC}_{2} \mathrm{H}_{5}\right)_{2}$. . $\mathrm{OH} \cdot \mathrm{NH}_{2} \cdot \mathrm{HCl}+\mathrm{H}_{2} \mathrm{O}$.

I. $0.3089 \mathrm{~g}$ Substanz gaben $0.5405 \mathrm{~g}$ Kohlensäure und $0.2002 \mathrm{~g}$ Wasser.

II. $0.3944 \mathrm{~g}$ Substanz gaben $0.2195 \mathrm{~g}$ Oxalsäure.

III. $0 \cdot 1996 g$ Substanz gaben $0.3582 g$ Jodsilber.

In 100 Theilen:

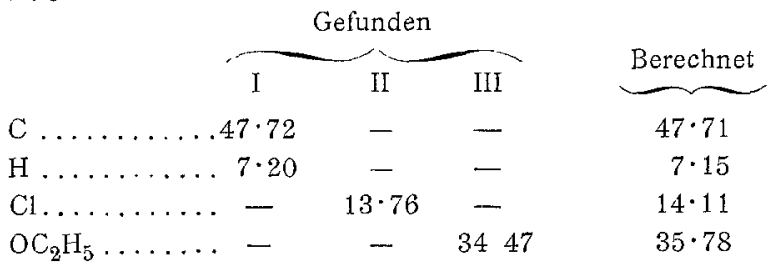

Auch das 3,5-Diäthoxy-4-Amidophenol lässt sich im freinZustande seiner Zersetzlichkeit wegen nicht darstellen. Bei 
Zugabe der theoretischen Menge von Ätzkali zur Lösung des Chlorhydrates scheidet sich eine weisse krystallinische Masse $a b$, welche indess sehr bald eine gelbe, weiterhin eine dunkelbraune Farbe annimmt, rasch tritt diese Farbenwandlung bei Anwesenheit eines kleinen Überschusses des Alkalis ein. Zur genaueren Unterscheidung des Chlorhydrates des 3,5-Diäthoxy4-Amidophenols von demjenigen des 3, 5-Diäthoxy-2-Amidophenols wurde auch aus dem ersteren durch Behandeln mit Essigsäureanhydrid ein

Triacetylderivat dargestellt. Die Bildung desselben erfolgt ganz analog, wie die des früher beschriebenen. Das Erhitzen mit Essigsäureanhydrid wurde auch in diesem Falle bis zum Aufhören der Entwicklung von Salzsäure, beziehungsweise von Chloracetyl fortgesetzt. Nach dem Abdestilliren des Anhydrids im Vacuum hinterbleibt ein ziemlich stark gefärbter, zähflüssiger Rückstand, der erst nach längerer Zeit krystallinisch erstarrt. Durch wiederholtes Umkrystallisiren desselben aus Ligroin wurde die Verbindung in Form völlig farbloser, lebhaft glänzender Krystallnadeln erhalten, deren Schmelzpunkt bei $81-83^{\circ} \mathrm{C}$. (uncorr.) liegt und die im Vacuum unzersetzt flüchtig sind. Die Analyse, die Äthoxyl- und Acetylbestimmung der über Schwefelsäure im Vacuum zur Gewichtsconstanz gebrachten Substanz ergab Werthe, die mit der Formel $\mathrm{C}_{6} \mathrm{H}_{2}\left(\mathrm{OC}_{2} \mathrm{H}_{5}\right)_{2} \mathrm{O} \cdot \mathrm{COCH}_{3} \mathrm{~N}$. $\left(\mathrm{COCH}_{3}\right)_{2}$ in völliger Übereinstimmung stehen.

I. $0.2445 \mathrm{~g}$ Substanz gaben $0.5293 \mathrm{~g}$ Kohlensäure und $0.1454 \mathrm{~g}$ Wasser.

II. $0 \cdot 2294 \mathrm{~g}$ Substanz gaben $0 \cdot 3216 \mathrm{~g}$ Jodsilber.

III. $0.2556 \mathrm{~g}$ Substanz gaben Essigsäure, welche $59 \cdot 2 \mathrm{~cm}^{3} 1 / 25$ norm. Kalilauge neutralisirt, entsprechend $0.101824 \mathrm{~g}$ Acetyl.

In 100 Theilen:

\begin{tabular}{|c|c|c|c|c|}
\hline & \multicolumn{3}{|c|}{ Gefunden } & \multirow[b]{2}{*}{ Berechnet } \\
\hline & I & II & III & \\
\hline $\mathrm{C}$ &. $.59 \cdot 04$ & - & - & $59 \cdot 44$ \\
\hline $\mathrm{H}$ & $6 \cdot 60$ & - & - & $6 \cdot 50$ \\
\hline $\mathrm{OC}_{2} \mathrm{H}_{5}$. & - & $26 \cdot 90$ & - & $27 \cdot 86$ \\
\hline $\mathrm{CH}_{3} \mathrm{CO}$ & - & - & $39 \cdot 83$ & $39 \cdot 93$ \\
\hline
\end{tabular}

Die Acetylirungen haben wir auch mit Rücksicht auf die mögliche Bildung eines Äthenylderivates mit Essigsäure allein 
und mit essigsaurem Natron und Essigsäure vorgenommen. Dabei hat das 3,5-Diäthoxy-4-Amidophenol keine Veränderung erlitten, während das 3,5-Diäthoxy-2-Amidophenol zum allergrössten Theile roth oder violett gefärbte harzige Producte liefert, und nur eine kleine Menge einer krystallinischen Verbindung gebildet wird, die aus den ätherischen Extracten gewonnen wurde. Da aber eine Reinigung nicht herbeigeführt werden konnte, wurde auf die nähere Untersuchung dieses Körpers nicht eingegangen, so dass es dahingestellt bleiben muss, ob aus dem 3,5-Diäthoxy-2-Amidophenol auf diesem Wege eine Monoacetyl-, beziehungsweise Äthenylverbindung entsteht. Um die angegebenen Stellungen unserer Amidophenole zu beweisen, haben wir die Einwirkung von Harnstoff auf dieselben vorgenommen und erhielten wir aus dem 3, 5-Diäthoxy-2-Amidophenolchlorhydrat das

\section{3, 5-Diäthoxy-Carbonyl-2-Amidophenol.}

Beim Erhitzen eines Gemisches des Chlorhydrates des 3, 5-Diäthoxy-2-Amidophenols (1 Mo1.) mit Harnstoff ( $1 \frac{1 / 2}{2}$ Mol.) verflüssigt sich die Masse bei circa $120-140^{\circ}$ und entwickelt bei $160^{\circ}$ lebhaft Ammoniak. Nachdem sich die Gasentwicklung verlangsamt hatte, wurde die inzwischen dunkelbraunroth gewordeñe Schmelze auf $170-185^{\circ}$ erhitzt. Als endlich nach circa 1" Stunde die Entstehung von Gasen nicht mehr beobachtet werden konnte, wurde erkalten gelassen und die Masse mit Waśser, dem etwas Essigsäure zugesetzt war, ausgekocht. Die Flüssigkeit färbt sich intensiv rothviolett, während ein kaum lösliches krystallinisches Product zurückbleibt. Dasselbe filtrirt man, wäscht es mit Wasser vollkommen aus und löst es zur weiteren Reinigung in siedendem Alkohol auf. Die noch violett gefärbte Lösung lässt sich durch Thierkohle fast vollkommen entfärben. Nach dem Abdestilliren des Lösungsmittels hinterbleibt eine gelblichweisse, deutlich krystallinische Masse, die nach Entfernung der Mutterlaugen in Benzol gelöst wurde. Diese eingeengte Lösung scheidet auf Zusatz von Ligroin beim Stehen prächtig glänzende, feine Krystallnadeln $a b$, die in Wasser nahezu unlöslich sind, leicht aber von siedendem Alkohol, Benzol und Essigäther aufgenommen werden. 
Der Schmelzpunkt dieser Verbindung liegt bei $192-195^{\circ} \mathrm{C}$. (uncorr.). Über diese Temperatur erhitzt, erleidet die Substanz keine Veränderung und scheint über $250^{\circ}$ unzersetzt flüchtig zu sein. Die Analyse und die Äthoxylbestimmung des bei $100^{\circ}$ getrockneten Präparates lieferten Werthe, welche zur Formel $\mathrm{C}_{7} \mathrm{H}_{3} \mathrm{NO}_{2}\left(\mathrm{OC}_{2} \mathrm{H}_{5}\right)_{2}$ führten. Es ergibt sich hiemit, dass das in Rede stehende Product als ein nach Formel III zusammengesetztes 3,5-Diäthoxy-Carbonyl-2-Amidophenol zu betrachten ist.

I. $0.2412 \mathrm{~g}$ Substanz gaben $0.5179 \mathrm{~g}$ Kohlensäure und $0.1281 \mathrm{~g}$ Wasser. II. $0.3491 \mathrm{~g}$ Substanz gaben $21 \mathrm{~cm}^{9}$ Stickstoff bei $18^{\circ} \mathrm{C}$. und $738.6 \mathrm{~mm}$ Druck.

III. $0.2017 g$ Substanz gaben $0.4261 g$ Jodsilber.

In 100 Theilen:

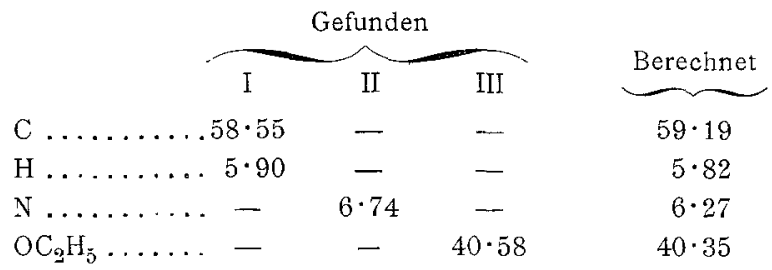

Das 3,5-Diäthoxy-4-Amidophenolchlorhydrat hingegen liefert bei der Behandlung mit Harnstoff einen substituirten, nach Formel IV constituirten Phenylharnstoff und verhält sich daher analog dem Phenylamin, welches, wie Fleischer ${ }^{1}$ gezeigt hat, bei entsprechenden Reactionsbedingungen einen (Mono-) Phenylharnstoff bildet.

\section{2, 6-Diäthoxy-4-Oxy-Phenylharnstoff.}

Das Chlorhydrat des 3, 5-Diäthoxy-4-Amidophenols haben wir mit etwas mehr als der berechneten Menge Harnstoff zusammengeschmolzen. Bei etwa $70^{\circ} \mathrm{schmilzt}$ die Substanz und beginnt Ammoniak zu entwickeln, beim weiteren Erhitzen erstarrt die Schmelze, um bei $160-170^{\circ}$ neuerlich flüssig zu werden. Bei dieser letzteren Temperatur hört nach einiger Zeit die Gasentwicklung auf. Nach dem Erkalten wurde die

1 Fleischer, B. 9, 995. 
braun gefärbte, deutlich krystallinische Schmelze mit grösseren Quantitäten warmen Wassers extrahirt, wodurch Salmiak und ein lösliches, dunkelgelbbraun gefärbtes Nebenproduct vom schwer löslichen substituirten Harnstoffe getrennt wurden. Derselbe wird in Alkohol gelöst und mit Thierkohle entfärbt. Aus dieser Lösung scheidet sich die Verbindung in undeutlich krystallinischen, dunkel gefärbten Krusten ab. Die von der Mutterlauge befreite Krystallmasse wird in Wasser unter Zusatz von etwas Essigsäure in der Siedehitze gelöst. Schon beim Abkühlen scheiden sich glasglänzende, kleine, prismatische Krystallnadeln $a b$, die nach dem Trocknen eine schwach gelbliche Farbe besitzen und bei $199 \cdot 5-201^{\circ} \mathrm{C}$. (uncorr.) schmelzen.

Die Analyse der bei $100^{\circ}$ getrockneten Substanz führte zur Formel $\mathrm{C}_{7} \mathrm{H}_{6} \mathrm{O}_{2} \mathrm{~N}_{2}\left(\mathrm{OC}_{2} \mathrm{H}_{5}\right)_{2}$.

I. $0 \cdot 2137 \mathrm{~g}$ Substanz gaben $0 \cdot 4300 \mathrm{~g}$ Kohlensäure und $0 \cdot 1333 \mathrm{~g}$ Wasser.

II. $0.1989 \mathrm{~g}$ Substanz gaben $21 \mathrm{~cm}^{3}$ Stickstoff bei $19^{\circ} \mathrm{C}$. und $736 \mathrm{~mm}$ Druck.

In 100 Theilen:

$\overbrace{\text { I }}^{\text {Gefunden }} \underbrace{\text { Berechnet }}_{\text {II }}$

Durch das verschiedene Verhalten der beiden DiäthoxyAmidophenole scheint die Constitution derselben festgestellt zu sein, und damit ist auch die Stellung der Nitrosoreste in den beiden Oximen gegeben. Um endlich zu ermitteln, ob die Einwirkungsproducte der salpetrigen Säure auf den Phloroglucindiäthyläther als Nitroso- oder Isonitrosoderivate anzusehen sind, wurde die eingangs besprochene Reduction der Triäthyläther vorgenommen.

Die Triäthyläther sind im grossen Ganzen nach dem Verfahren Moldauer's dargestellt worden, da aber durch einige Verbesserungen die Ausbeuten wesentlich gesteigert werden konnten, wollen wir einige Bemerkungen über die 


\section{Einwirkung von Jodäthyl auf das 3, 5-Diäthoxy-ortho- Chinon-2-Monoxim}

hier einflechten. Vor Allem zeigte es sich, dass die Isolirung des Kalisalzes des Oxims nicht unbedingt nöthig ist. Bei Einhaltung des folgenden Receptes haben wir die besten Resultate erzielt. In die siedende Lösung von je $40 \mathrm{~g} 3,5$-Diäthoxy-orthoChinon-2-Monoxim in $250 \mathrm{~cm}^{3}$ absoluten Alkohol wird die Lösung von $8 \mathrm{~g}$ Kalium (das ist etwas mehr als die theoretische Menge) in $100 \mathrm{~cm}^{3}$ absoluten Alkohol eingetragen. Hiebei bildet sich unter Aufkochen das Kalisalz, welches sich nach einigen Augenblicken in gelbgrün gefärbten, feinen Krystallfäden abscheidet. Die etwas abgekühlte (circa $40^{\circ}$ warme) Masse wurde mit $40 \mathrm{~g}$ Jodäthyl vermischt und am Rückflusskühler so lange im Sieden erhalten, bis eine herausgenommene, in Wasser gelöste Probe völlig neutrale Reaction zeigte, was nach etwa $1 \frac{1}{2}$ Stunden eintrat. Nun wird etwa drei Viertel des Alkohols abdestillirt, der Rückstand mit circa $500 \mathrm{~cm}^{3}$ Wasser vermischt und mit Benzol wiederholt ausgeschüttelt. Die vereinten benzolischen Extracte wurden mit Wasser, dem etwas Kalilauge zugesetzt war, so lange ausgeschüttelt, als sich die Kalilauge noch roth färbt. Der nach dem Abdunsten des Benzols hinterbleibende Rückstand, welcher 3, 5-Diäthoxy-Äthenyl-2-Amidophenol (Äthyl-Pyriphloron-Diäthyläther, $A$ ) neben 3, 5-Diäthoxy-ortho-Chinon-2-Monoximäthyläther $(B)$ enthält, wird in siedendem Ligroin gelöst. Erstere Verbindung ist in demselben leichter löslich als letztere, es scheidet sich demnach schon beim Abkühlen der Lösung eine reichliche Menge der Sub$\operatorname{stanz} B$ ab. Nachdem von derselben abgesaugt wurde, wird das Ligroin im Vacuum vollkommen vertrieben, der Rückstand in wenig Alkohol gelöst und nach dem Abkühlen mit Eiswasser so lange versetzt, bis auf weitere Zugabe desselben keine Ausscheidung mehr erfolgt. Durch diese Behandlung gelingt es, die letzten Reste des in ganz verdünntem Alkohol äusserst leicht löslichen Triäthyläthers $(B)$ von dem in diesem Lösungsmittel nahezu unlöslichen Anhydroproducte $(A)$ zu trennen. Die aus den $B$ enthaltenden Filtraten durch Schütteln mit Äther wiedergewonnene Substanz wird mit der bereits früher aus der 
Ligroinlösung abgeschiedenen Hauptmenge vereint, neuerdings in Benzol gelöst und, wie früher angegeben, mit verdünnter Kalilauge geschüttelt um die letzten Spuren des roth gefärbten amorphen Nebenproductes $z u$ entfernen. Die Benzollösung liefert beim Abdunsten grosse tafelförmige Krystalle, die eine dunkelrothgelbe Farbe besitzen und welche beim Zerreiben ein zinnoberrothes Pulver liefern. Durch wiederholtes Umkrystallisiren aus absolutem Äther erhält man die Verbindung vollkommen rein. Nicht selten bilden sich beim langsamen $\mathrm{Ab}$ dunsten ätherischer Lösungen grosse, wohl ausgebildete, trikline Krystalltafein, deren Messung Herr Hofrath v. Lang vorzunehmen die Güte hatte.

»Die Krystalle sind asymmetrisch, eine Combination der Flächen 100, 001, 110, 111, 111; durch das Vorherrschen der Fläche 100 sind sie tafelförmig.

Aus den beobachteten Winkeln:

$$
\begin{aligned}
& 100.110=53^{\circ} 38^{\prime} \\
& 100.110=66 \quad 27 \\
& 100.111=62 \quad 15 \\
& 111.111=50 \quad 7 \\
& 111.110=5930
\end{aligned}
$$

folgt das Axenverhältniss

$$
a: b: c=1: 0 \cdot 6322: 0 \cdot 4857
$$

und für die Axenwinkel:

$$
\begin{aligned}
& b c=62^{\circ} 24^{\prime} \\
& c a=90 \quad 10 \\
& a b=98 \quad 24
\end{aligned}
$$

Der Schmelzpunkt wurde zu $92^{\circ}$ C. (uncorr.) gefunden (Moldauer gibt denselben zu $106^{\circ} \mathrm{C}$. an).

Die Analyse und Äthoxylbestimmung der im Vacuum über Schwefelsäure zur Gewichtsconstanz gebrachten Substanz stimmt auf die Formel $\mathrm{C}_{6} \mathrm{H}_{2}\left(\mathrm{OC}_{2} \mathrm{H}_{5}\right)_{2}$. O. $\mathrm{NOC}_{2} \mathrm{H}_{5}$.

I. $0.2866 g$ Substanz gaben $0.6294 g$ Kohlensäure und $0.1876 g$ Wasser.

II. $0 \cdot 1905 \mathrm{~g}$ Substanz gaben $0.5019 \mathrm{~g}$ Jodsilber. 
In 100 Theilen:

\begin{tabular}{|c|c|c|}
\hline \multicolumn{2}{|c|}{ Gefunden } & \multirow[b]{2}{*}{ Berechnet } \\
\hline I & II & \\
\hline $.59 \cdot 89$ & - & $60 \cdot 25$ \\
\hline$\ldots \ldots \ldots \ldots, 7 \cdot 27$ & - & $7 \cdot 11$ \\
\hline$\ldots \ldots \ldots-$ & $50 \cdot 60$ & $56 \cdot 48$ \\
\hline
\end{tabular}

Die Fällung $A$ wird durch Auflösen in wenig Alkohol und neuerliche Abscheidung mit Eiswasser zunächst vorgereinigt, getrocknet und dann im Vacuum der Destillation unterworfen. Bei $176.5^{\circ}$ C. (16 mm Druck) siedet die Verbindung. Die Dämpfe condensiren sich zu einem schwach röthlichgelb gefärbten Öl, welches blätterig krystallinisch erstarrt. Dieses Product wird endlich aus Alkohol in der Weise umkrystallisirt, dass zur kalten Lösung so lange Wasser zugetropft wurde, bis eine leichte Trübung eintrat. Beim Stehen über Schwefelsäure scheiden sich dann völlig farblose, vollkommen reine Krystallblättchen $\mathrm{ab}$, die den Schmelzpunkt $58-59^{\circ} \mathrm{C}$. (uncorr.) zeigen.

Die Analyse und Äthoxylbestimmung erwies die Identität der auf diese Weise erhaltenen Substanz mit der von Moldauer dargestellten.

I. $0 \cdot 2360 \mathrm{~g}$ Substanz gaben $0.5582 \mathrm{~g}$ Kohlensäure und $0.1467 \mathrm{~g}$ Wasser. If. $0.6166 \mathrm{~g}$ Substanz gaben $1.3329 \mathrm{~g}$ Jodsilber.

In 100 Theilen:

$\overbrace{\text { I }}^{\text {Gefunden }} \underbrace{\text { Berechnet }}_{\text {II }}$

Einwirkung von Zinnchlorür und Salzsäure auf den 3, 5-Diäthoxy-ortho-Chinon-2-Monoximäthyläther.

Die Reduction wurde in derselben Weise wie die des 3,5Diäthoxy-ortho-Chinonoxims mit Zinnchlorür vorgenommen und waren auch alle die dort angegebenen Erscheinungen auch hier zu beobachten. Die aus der Reactionsmasse durch das angegebene Verfahren gewonnene Salzsäureverbindung zeigt alle Eigenschaften des Chlorhydrates des 3,5-Diäthoxy- 
2-Amidophenols, wie Eisenreaction etc. und liess sich durch die Analyse und Äthoxylbestimmung mit demselben identificiren.

I. $0.3514 \mathrm{~g}$ Substanz geben $0.6596 \mathrm{~g}$ Kohlensäure und $0.2121 \mathrm{~s}$ Wasser.

II. $0.3665 \mathrm{~g}$ Substanz geben $0.2241 \mathrm{~g}$ Chlorsilber.

III. $0.2438 \mathrm{~g}$ Substanz geben $0.4765 \mathrm{~g}$ Jodsilber.

In 100 Theilen:

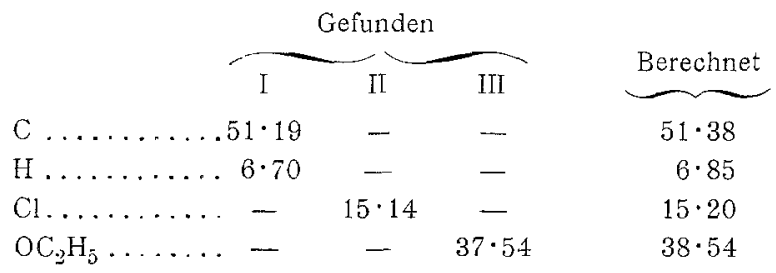

Überdies liefert das Reductionsproduct des Oximäthers bei Behandlung mit Essigsäureanhydrid ein Triacetylderivat, welches den Fusionspunkt $110-112^{\circ}$ zeigte und bei der Analyse, Äthoxyl- und Acetylbestimmung Zahlen lieferte, die mit den Zahlen des früher beschriebenen Acetylderivates des 3,5Diäthoxy-2-Amidophenols völlig übereinstimmen.

I. $0 \cdot 2181 \mathrm{~g}$ Substanz gaben $04711 \mathrm{~g}$ Kohlensäure und $0.1301 \mathrm{~g}$ Wasser.

II. $0 \cdot 2433 g$ Substanz gaben $0.3456 \mathrm{~g}$ Jodsilber.

III. $0.2734 \mathrm{~g}$ Substanz gaben Essigsäure, welche $63.4 \mathrm{~cm}^{3} 1 / 25$ norm. Kalilauge neutralisirten, entsprechend $0.109048 \mathrm{~g}$ Acetyl.

In 100 Theilen:

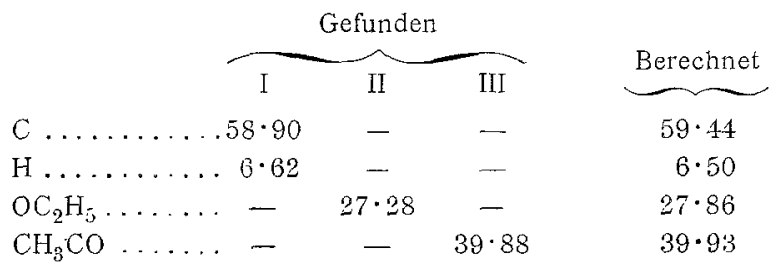

Einwirkung von Zinnchlorür und Salzsäure auf den 3, 5-Diäthoxy-para-Chinon-4-Monoximäthyläther.

Die zu den Versuchen verwendete Substanz wurde aus dem 3,5-Diäthoxy-para-Chinon-4-Monoxim durch Einwirkung von Jodäthyl und Kalilauge genau nach Moldauer's Angaben dargestellt. Die Reduction des Oximäthers mit Zinnchlorür und 
Salzsäure verlief, wie bei dem zugeordneten Oxim angegeben wurde. Auch die Aufarbeitung und Reindarstellung ist in der daselbst angegebenen Weise vorgenommen worden. Das Reductionsproduct war sehr leicht durch den Krystallwassergehalt, durch die Analyse und Äthoxylbestimmung mit dem Chlorhydrat des 3,5-Diäthoxy-4-Amidophenols zu identificiren.

I. $0.2121 \mathrm{~g}$ Substanz liefern $0.3704 \mathrm{~g}$ Kohlensäure und $0.1393 \mathrm{~g}$ Wasser.

II. $0.3519 \mathrm{~g}$ Substanz liefern $0.2005 \mathrm{~g}$ Chlorsilber.

III. $0.2696 \mathrm{~g}$ Substanz liefern $0.4965 \mathrm{~g}$ Jodsilber.

In 100 Theilen:

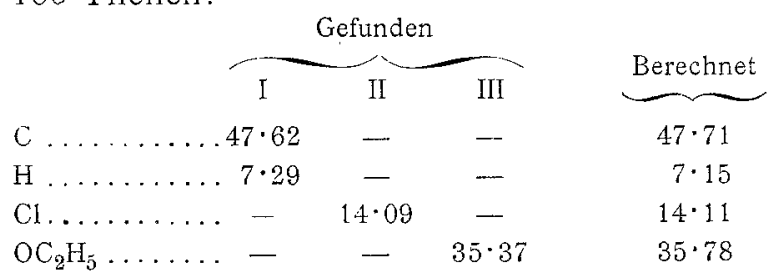

Zum Überflusse haben wir auch das Einwirkungsproduct von Essigsäureanhydrid auf das Chlorhydrat dargestellt. Nach entsprechender Reinigung zeigte es den Schmelzpunkt von $81-83^{\circ}$ C. (uncorr.) und gab die Analyse und Acetylbestimmung die folgenden Zahlen, welche die Identität mit dem Triacetylderivate des 3, 5-Diäthoxy-4-Amidophenols ausser $Z$ weifel stellten.

I. $0.2176 \mathrm{~g}$ Substanz geben $0.4720 \mathrm{~g}$ Kohlensäure und $0.1337 \mathrm{~g}$ Wasser.

II. $0 \cdot 2080 \mathrm{~g}$ Substanz geben Essigsäure, welche $49 \cdot 12 \mathrm{~cm} n^{3} 1 / 25$ norm. Kalilauge neitralisirten, entsprechend $0 \cdot 0844864 \mathrm{~g}$ Acetyl.

In 100 Theilen:

\begin{tabular}{|c|c|c|c|}
\hline & \multicolumn{2}{|c|}{ Gefunden } & \multirow[b]{2}{*}{ Berechnet } \\
\hline & I & II & \\
\hline$C \ldots \ldots$ & $.59 \cdot 15$ & - & $59 \cdot 44$ \\
\hline$\ldots$. & $.6 \cdot 82$ & - & $6 \cdot 50$ \\
\hline $\mathrm{CH}_{3} \mathrm{CO}$ & - & $40 \cdot 61$ & $39 \cdot 93$ \\
\hline
\end{tabular}

Durch die mitgetheilten Untersuchungsresultate erhalten die in der Einleitung gegebenen Betrachtungen ihre Begründung.

Durch die folgende Zusammenstellung sollen die Verschiedenheiten in den Eigenschaften und dem Verhalten der beiden Diäthoxychinonmonoxime besonders hervorgehoben werden. 


\begin{tabular}{|c|c|c|}
\hline & $\begin{array}{c}\text { 3,5-Diäthoxy-o-Chinon- } \\
\text { 2-Monoxim }\end{array}$ & $\begin{array}{c}\text { 3,5-Diäthoxy- } p \text {-Chinon- } \\
\text { 4-Monoxim }\end{array}$ \\
\hline Farbe.. & rothe Krystallblättchen & $\begin{array}{c}\text { hellgelb gefärbte kleine } \\
\text { Nadeln }\end{array}$ \\
\hline Löslichkeit $\ldots . . \ldots$. & in Äther leicht löslich & in Äther nahezu unlöslich \\
\hline Schmelzpunkt....... & $117^{\circ} \mathrm{C}$ & $195^{\circ} \mathrm{C}$ \\
\hline Farbe des Kalisalzes & grün & violett \\
\hline Farbe des Silbersalzes. & braunroth & grün \\
\hline $\begin{array}{c}\text { Gibt bei Behandlung mit } \\
\text { Kali und Jodäthyl... }\end{array}$ & $\begin{array}{c}\text { 3,5-Diäthoxy-o-Chinon- } \\
\text { 2-Monoximäther }\end{array}$ & $\begin{array}{c}\text { 3,5-Diäthoxy- } p \text {-Chinon- } \\
\text { 4-Monoximäther }\end{array}$ \\
\hline Farbe und Krystallform & $\begin{array}{c}\text { zinnoberrothe trikline } \\
\text { Tafeln }\end{array}$ & gelbe feine Nadeln \\
\hline Schmelzpunkt... & $92^{\circ} \mathrm{C}$ & $118^{\circ} \mathrm{C}$ \\
\hline $\begin{array}{c}\text { Durch Zinnchlorür ent- } \\
\text { steht das Chlorhydrat } \\
\text { des . . . . . . . }\end{array}$ & $\begin{array}{l}\text { 3,5-Diäthoxy-2-Amido- } \\
\text { phenol }\end{array}$ & $\begin{array}{c}\text { 3, 5-Diäthoxy-4-Amido- } \\
\text { phenol }\end{array}$ \\
\hline Krystallwassergehalt & krystallisirt ohne Wasser & $\begin{array}{c}\text { krystallisirt mit } 1 \text { Mol. } \\
\text { Wasser }\end{array}$ \\
\hline Eisenreaction $\ldots \ldots \ldots$ & dunkelroth & gelb \\
\hline $\begin{array}{r}\text { Schmelzpunkt der Tri- } \\
\text { acetylverbindung. } . .\end{array}$ & $112^{\circ} \mathrm{C}$ & $83^{\circ} \mathrm{C}$ \\
\hline $\begin{array}{c}\text { Gibt bei Behandiung mit } \\
\text { Harnstoff ......... }\end{array}$ & $\begin{array}{c}\text { 3, כ-Diäthoxy-Carbonyl- } \\
\text { 2-Amidophenol }\end{array}$ & $\begin{array}{l}\text { 2, 6-Diäthoxy-4-Oxy- } \\
\text { Phenylharnstoff }\end{array}$ \\
\hline Schmelzpunkt. & $195^{\circ} \mathrm{C}$ & $201^{\circ} \mathrm{C}$ \\
\hline
\end{tabular}

Zur Auf klärung der Constitution des Moldauer'schen Äthylpyriphlorondiäthyläthers haben wir die Spaltung desselben mit Zinn und Salzsäure, mit Salzsäure allein und die Einwirkung von Natriumamalgam vorgenommen. Letztere Reaction liefert in ziemlich glatter Ausbeute das

\section{Monoacetylderivat des 3,5-Diäthoxy-2-Amidophenols,} welchem die Formel<smiles>CC(=O)NC1COCC1OC(C)=O</smiles> 
zuzusprechen ist. Die Darstellung führt man am zweckmässigsten folgendermassen aus. Die alkoholische, mit Wasser bis zum Eintreten einer schwachen Trübung verdünnte Lösung behandelt man in mässiger Wärme $\left(60-70^{\circ}\right)$ mit 4 procentigem Natriumamalgam, bis eine herausgenommene Probe auf Zusatz von Wasser keine Abscheidung der ursprünglichen Substanz mehr gab. Die anfänglich farblose Flüssigkeit nimmt allmälig eine röthlichgelbe Farbe an, die zum Schluss in gelbbraun ïbergeht. In der Regel ist nach circa 60 Stunden die Reaction vollendet; während dieser Zeit wurde die Lösung einigemal mit Schwefelsäure partiell neutralisirt. Schliesslich wird die vom unangegriffenen Amalgam abgegossene Flüssigkeit schwach angesäuert und mit Benzol ausgeschüttelt. Beim Abdunsten der vereinten, gelblichbraun gefärbten Benzolextracte wird ein dicktlüssiges, dunkles Öl erhalten, welches beim Stehen sehr bald krystallinisch erstarrt. Die von der dunklen Lauge durch Absaugen getrennten Krystalle werden mit wenig absolutem Ather gewaschen und dann neuerlich in Benzol gelöst. Die mit Thierkohle entfärbte Lösung gibt nach dem Abdunsten eines Theiles des Lösungsmittels auf Zusatz von Ligroin nach einiger Zeit eine Abscheidung völlig farbloser Krystallnadeln, die die Flüssigkeit breiig erfüllen. Dieses Product wurde schliesslich nochmals aus verdünntem Alkohol umkrystallisirt. So dargestellt, bildet die Verbindung ein Aggregat von lockeren, feinen, schwach seidenglänzenden, haarförmigen Nadeln, die den Schmelzpunkt $122 \cdot 5-123 \cdot 5^{\circ} \mathrm{C}$. (uncorr.) zeigen. Sie ist in Benzol, sowie 1 Alkohol leicht löslich, schwieriger in $\overparen{A}$ ther und Ligroin; Wasser nimmt sie nur in der Siedehitze in geringen Quantitäten auf und scheidet beim Abkühlen wieder feine Krystallnadeln ab. Die Lösung reagirt neutral. Beim Erhitzen der in verdünnter Schwefelsäure gelösten Substanz tritt Essigsäureabspaltung ein. Die für die Analyse, Äthoxylbestimmung und Acetylbestimmung im Vacuum zur Gewichtsconstanz gebrachte Substanz gab Zahlen, welche auf die früher angegebene Formel stimmten.

I. $0.2582 \mathrm{~g}$ Substanz gaben $0.5701 \mathrm{~g}$ Kohlensäure und $0.1567 \mathrm{~g}$ Wasser.

II. $0 \cdot 2597 \mathrm{~g}$ Substanz gaben $14 \cdot 7 \mathrm{~cm}^{3}$ Stickstoff bei $21^{\circ} \mathrm{C}$. und $731.9 \mathrm{~mm}$ Druck. 
III. $0 \cdot 1982 \mathrm{~g}$ Substanz gaben $0 \cdot 3910 \mathrm{~g}$ Jodsilber.

IV. $0.3915 \mathrm{~g}$ Stubstanz gaben Essigsäure, welche $39 \mathrm{~cm}^{3} 1 / 25$ norm. Kalilauge neutralisirten, entsprechend $0.06708 \mathrm{~g}$ Acetyl.

In 100 Theilen:

\begin{tabular}{|c|c|c|c|c|}
\hline \multicolumn{4}{|c|}{ Gefunden } & \multirow{2}{*}{ Berechnet } \\
\hline I & II & III & IV & \\
\hline C $\ldots \ldots \ldots 60 \cdot 21$ & - & - & - & $60 \cdot 25$ \\
\hline$\ldots \ldots 6 \cdot 7 \cdot 4$ & 一 & - & - & $7 \cdot 11$ \\
\hline$\ldots-$ & $6 \cdot 19$ & - & $\ldots$ & $\tilde{\jmath} \cdot 85$ \\
\hline $\mathrm{OC}_{2} \mathrm{H}_{5}$ & - & $37 \cdot 89$ & - & $37 \cdot 65$ \\
\hline $\mathrm{CH}_{3} \cdot \mathrm{CO} \ldots \ldots$ & - & - & $17 \cdot 14$ & $17 \cdot 99$ \\
\hline
\end{tabular}

Ihrer Constitution entsprechend löst sich die Verbindung in verdünnten Alkalien und geht dieselbe auch unter Abspaltung von Wasser in hoher Temperatur in das 3, 5-Diäthoxy-Äthenyl2-Amidophenol über. Beim Erhitzen einer Probe mit Essigsäureanhydrid erhielten wir ein Acetylproduct, welches den Schmelzpunkt $110-112^{\circ} \mathrm{C}$. (uncorr.) zeigte und demzufolge als Triacetylderivat des 3,5-Diäthoxy-2-Amidophenols $z u$ betrachten ist.

In einer für die Constitution des 3,5-Diäthoxy-Äthenyl2-Amidophenols höchst charakteristischen Weise zerfällt dasselbe bei der

\section{Einwirkung von Salzsäure.}

Durch Zusammenbringen der Base mit concentrirter Salzsäure entsteht ein krystallisirtes, durch Wasser in seine Componenten spaltbares Chlorhydrat, welches auch befähigt ist, eine Platindoppelverbindung zu bilden. Verdünnte Salzsäure aber ist in der Kälte ohne Einwirkung und vermag auch nicht die Substanz zu lösen; kocht man durch längere Zeit, so geht das 3,5-Diäthoxy-Äthenyl-2-A.midophenol endlich in Lösung, die Flüssigkeit färbt sich dabei roth und scheidet beim Abkühlen weder die Base, noch ihr Chlorhydrat ab, sondern liefert eine Substanz, welche mit dem salzsauren Salz des 3, 5-Diäthoxy2-Amidophenols die grösste Ähnlichkeit zeigt und so wie dieses eine rothe Eisenreaction zeigt. Um bei der Spaltung des Pyriphlorons die Bildung roth gefärbter Zersetzungsproducte $z u$ vermeiden, sind wir in folgender Weise verfahren. $15 \mathrm{~g}$ der 
Base wurden mit $100 \mathrm{~cm}^{3}$ verdünnter Salzsäure $\left(30 \mathrm{~cm}^{3}\right.$ gewöhnliche Salzsäure, $70 \mathrm{~cm}^{3}$ Wasser), welcher $1 \frac{1}{2} \mathrm{~g}$ Zinnchlorür zugesetzt waren, so lange gekocht, bis die anfangs unter Wasser geschmolzene Substanz vollständig gelöst war.' Der Zinnchlorürzusatz ist nothwendig, um einer Oxydation, welche durch den Luftsauerstoff beim längeren Erhitzen bedingt ist, vorzubeugen. Die völlig farblose Lösung wird im Vacuum abdestillirt. Das Destillat haben wir mit Silberoxyd neutralisirt. Das Filtrat vom ausfallenden Silberchlorid liefert beim Concentriren eine reichliche Ausscheidung eines prächtig krystallisirten Silbersalzes, das sich durch eine Silberbestimmung als essigsaures Silber erkennen liess.

$0.3667 g$ Substanz gaben $0.2365 g$ Siber.

In 100 Theilen:

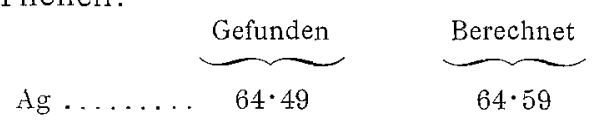

Der Destillationsrückstand ist in Wasser ziemlich leicht löslich und wurde behufs Entfernung des Zinns mit Schwefelwasserstoff behandelt. Das Filtrat vom Schwefelzinn liefert nach dem Abdestilliren des Lösungsmittels im Vacuum eine völlig weisse Masse, die aus haarfeinen Krystallnadeln bestand. Dieselben geben beim Umkrystallisiren aus salzsäurehältigem Wasser eine Verbindung, die alle Eigenschaften des 3, 5-Diäthoxy-2-Amidophenolchlorhydrates zeigt, wie dieses die Neigung besitzt, in wässeriger Lösung sich roth zu färben und bei der Analyse und Äthoxylbestimmung mit demselben völlig übereinstimmende Werthe liefert.

I. $0.2996 g$ Substanz geben $0.5607 g$ Kohlensäure und $0.1851 \mathrm{~g}$ Wasser.

II. $0 \cdot 4579 g$ Substanz geben $0 \cdot 2773 \mathrm{~g}$ Chlorsilber.

III. $0 \cdot 2220 \mathrm{~g}$ Substanz geben $0 \cdot 4285 \mathrm{~g}$ Jodsilber.

In 100 Theilen:

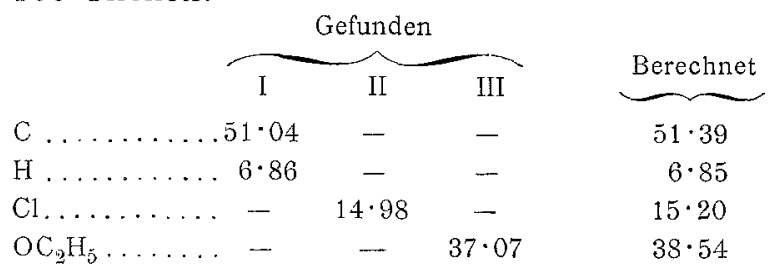


Die Identität dieses Productes mit dem Chlorhydrate des 3,5-Diäthoxy-2-Amidophenols liess sich wieder durch die Darstellung des Acetylderivates, welche wir in der mehrfach beschriebenen Weise vornahmen, beweisen. Den Schmelzpunkt der Verbindung fanden wir bei $110-112^{\circ}$ und gaben die analytischen Bestimmungen Werthe, die mit den für das Triacetylproduct des 3,5-Diäthoxy-2-Amidophenol berechneten in bester Übereinstimmung stehen.

I. $0.2494 \mathrm{~g}$ Substanz liefern $0.5409 \mathrm{~g}$ Kohlensäure und $0.1497 \mathrm{~g}$ Wasser.

II. $0 \cdot 2450 \mathrm{~g}$ Substanz liefern $0 \cdot 3461 \mathrm{~g}$ Jodsilber.

III. $0.2971 \mathrm{~g}$ Substanz liefern Essigsäure, welche $67.58 \mathrm{~cm}^{3} 1 / 25$ norm. Kalilauge neutralisirt, entsprechend $0 \cdot 116238 \mathrm{~g}$ Acetyl.

In 100 Theilen:

$\begin{array}{lllll}\text { I } & \text { II } & \text { III } & \underbrace{\text { Berechnet }}_{59 \cdot 44} \\ \mathrm{C} \ldots \ldots \ldots \ldots & 59 \cdot 14 & - & - & 6 \cdot 50 \\ \mathrm{H} \ldots \ldots \ldots & 6 \cdot 66 & - & - & 27 \cdot 86 \\ \mathrm{OC}_{2} \mathrm{H}_{5} \ldots \ldots \ldots & - & 27 \cdot 13 & - & 39 \cdot 93 \\ \mathrm{CH}_{3} . \mathrm{CO} \ldots \ldots & - & - & 39 \cdot 12 & \end{array}$

Auch beim Behandeln des 3, 5-Diäthoxy-Äthenyl-2-Amidophenols mit Zinn und Salzsäure tritt die Bildung von Hydroproducten nicht ein, sondern es wird wie durch Chlorwasserstoffsäure allein die Spaltung in das 3,5-Diäthoxy-2-Amidophenol und in Essigsäure herbeigeführt.

Beim Anwenden von concentrirter Salzsäure findet ausser dieser Zersetzung auch noch die Abspaltung eines Äthyls statt. Die Lösung der Äthenylverbindung erfolgt ziemlich rasch, und wenn das Erhitzen so lange fortgesetzt wird, bis eine herausgenommene Probe mit Wasser die ursprüngliche Substanz nicht mehr liefert, so erhält man nach dem Abdestilliren das Reactionsproduct in Form weisser, asbestartiger Nadeln, welche bei der Analyse und Äthoxylbestimmung Werthe lieferten, aus welchen sich die Formel $\mathrm{C}_{6} \mathrm{H}_{2}\left(\mathrm{OC}_{2} \mathrm{H}_{5}\right)(\mathrm{OH})_{2} \mathrm{NH}_{2} \cdot \mathrm{HCl}+\mathrm{H}_{2} \mathrm{O}$ ableiten liess.

I. $0 \cdot 3143 g$ Substanz geben $0 \cdot 4876 g$ Kohlensäure und $0 \cdot 1773 g$ Wasser.

II. $0 \cdot 3102 g$ Substanz geben $0 \cdot 2013 g$ Chlorsilber.

III. $0 \cdot 2106 g$ Substanz geben $0 \cdot 2178 g$ Jodsilber. 
In 100 Theilen:

\begin{tabular}{|c|c|c|c|}
\hline & Gefunde & & \\
\hline I & II & III & Berechnet \\
\hline$\ldots 42 \cdot 31$ & - & - & $42 \cdot 95$ \\
\hline$H \ldots \ldots \ldots 6 \cdot 26$ & - & - & $6 \cdot 26$ \\
\hline $\mathrm{C} 1 \ldots \ldots \ldots-$ & $16 \cdot 05$ & - & $15 \cdot 88$ \\
\hline $\mathrm{OC}_{2} \mathrm{H}_{5}$ & - & $19 \cdot 86$ & $20 \cdot 13$ \\
\hline
\end{tabular}

Die Bildung des Monoacetylderivates des 3, 5-Diäthoxy2-Amidophenols aus dem 3,5-Diäthoxy-Äthenyl-2-Amidophenol, sowie die Spaltung desselben mit Salzsäure liefern den stringenten Beweis für die Richtigkeit der Constitution. Diese ist aber anderseits ein weiterer Beleg für die Orthostellung der NOH-Gruppe im 3, 5-Diäthoxy-ortho-Chinon-2-Monoxim.

Ausser den beschriebenen Reactionen wurden noch einige Umsetzungen der Äthenylverbindung untersucht, unter anderen auch die

\section{Einwirkung von Phosphorpentachlorid.}

Lässt man auf $5 g$ 3, 5-Diäthoxy-Äthenyl-2-Amidophenol, welches in circa $20 \mathrm{~cm}^{3}$ Phosphoroxychlorid gelöst ist, $5 \mathrm{~g}$ Phosphorpentachlorid einwirken, so färbt sich die Flüssigkeit erst grün und entfärbt sich beim Erwärmen auf dem Wasserbade, wobei eine ziemlich lebhafte Salzsäureentwicklung eintritt. Sobald dieselbe ihr Ende erreicht hat, wird das Phosphoroxychlorid und das überschüssige Phosphorpentachlorid im Vacuum abdestillirt, und es bleibt ein krystallinischer, gelblichweiss gefärbter Rückstand, der sich bei dem Drucke von $17.5 \mathrm{~mm}$ bei $200-210^{\circ} \mathrm{C}$, ohne Zersetzung $\mathrm{zu}$ erleiden, destilliren lässt. Durch Wiederholung dieser Operation erhält man endlich eine bei $201-202^{\circ} \mathrm{C}$. (uncorr., Druck $17.5 \mathrm{~mm}$ ) constant siedende, bald krystallinisch erstarrende Flüssigkeit. Aus absolutem Äther umkrystallisirt, gibt dieses Product ein lockeres Haufwerk von schwach seidenglänzenden Nadeln. Dieselben zeigen den Schmelzpunkt $82-85^{\circ} \mathrm{C}$. (uncorr.), sind in Wasser und Alkalien unlöslich, leicht löslich aber in Alkohol, Äther, Chloroform, Benzol. Concentrirte Salzsäure löst die Verbindung, auf Zusatz von Wasser findet Abscheidung derselben statt. 
Für die analytischen Bestimmungen wurde die Substanz im Vacuum über Schwefelsäure zur Constanz gebracht und ergaben dieselben Zahlen, aus welchen die Formel $\mathrm{C}_{12} \mathrm{H}_{16} \mathrm{NClO}_{4}$ abgeleitet werden konnte.

I. $0.2997 g$ Substanz gaben $0.6187 \mathrm{~g}$ Kohlensäure und $0.1537 \mathrm{~g}$ Wasser.

II. $0.3228 \mathrm{~g}$ Substanz gaben $0 \cdot 1732 \mathrm{~g}$ Chlorsilber.

Iil. $0 \cdot 2155 g$ Substanz gaben $0 \cdot 3850 g$ Jodsilber.

In 100 Theilen:

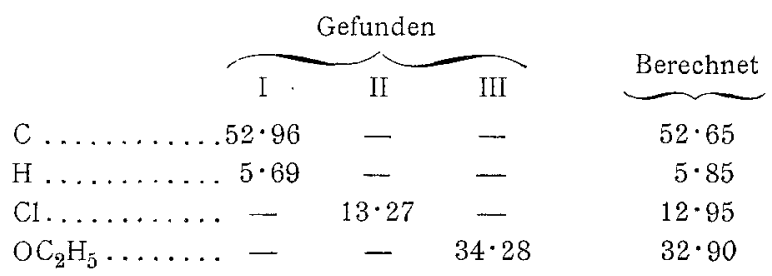

Aus dem Resultate der Äthoxylbestimmung geht hervor, dass in der Verbindung $2 \mathrm{OC}_{2} \mathrm{H}_{5}$-Reste vorhanden sind. Weiterhin konnten wir feststellen, dass beim anhaltenden Erhitzen des Chlorproductes mit Salzsäure oder Zinn und Salzsäure Abspaltung von Essigsäure erfolgt. Trotz dieser Ergebnisse sind wir nicht in der Lage angeben zu können, ob der Eintritt des Chlors im Benzolrest oder in der Seitenkette erfolgt war und behalten uns vor, hierüber Mittheilung zu machen.

Die Entstehung dieser Verbindung dürfte in der Weise $z \mathrm{u}$ Stande kommen, dass ein durch Anlagerung von $\mathrm{Cl}_{2}$ an das 3, 5-Diäthoxy-Äthenyl-2-Amidophenol entstandenes Zwischenproduct sich in einer späteren Phase mit der Phosphorsäure, die im Phosphoroxychlorid wahrscheinlich enthalten war, unter Salzsäureabspaltung in das Chlorproduct umwandelt, welches um $\mathrm{Cl}$ und $\mathrm{OH}$ mehr enthält als die Äthenylverbindung.

Zum Schlusse sei es uns gestattet, Herrn Hofrath v..Lang für seine Liebenswürdigkeit, mit der er die in dieser Arbeit angeführten Messungen vorzunehmen die Güte hatte, unseren Dank auszusprechen. 